\title{
Auger electron spectroscopy analysis of grain boundary microchemistry in an $\mathrm{Al}-\mathrm{Cu}-\mathrm{Li}$ alloy
}

\author{
Noémie Ott ${ }^{\mathrm{a}, \dagger}, *$, Yuanming Yan $^{\mathrm{a}, \uparrow}$, Sridhar Ramamurthy ${ }^{\mathrm{b}, \dagger}$, Shravan Kairy $^{\mathrm{a}}$, Nick Birbilis ${ }^{\mathrm{a}}$ \\ ${ }^{a}$ Department of Materials Science and Engineering, Monash University, Clayton, VIC, \\ Australia \\ ${ }^{\mathrm{b}}$ Surface Science Western, University of Western Ontario, London, ON, Canada
}

*Corresponding author: noemie.ott@ monash.edu (N. Ott) / Tel: +61 399054941.

$\dagger$ These authors contributed equally

\begin{abstract}
In situ impact fracture combined with Auger electron spectroscopy (AES) was employed to determine grain boundary (GB) microchemistry, namely lithium (Li) concentration, for an Al$\mathrm{Cu}-\mathrm{Li}$ alloy. The $\mathrm{Li} / \mathrm{Al}$ ratio of $\mathrm{GBs}$ in the naturally aged condition was revealed to be significantly higher than in the overaged condition (or in the bulk alloy). GB fracture surfaces for the naturally aged alloy were depleted in $\mathrm{Cu}$, whereas in the overaged condition the $\mathrm{GB}$ were depleted in $\mathrm{Li}$ and enriched in $\mathrm{Cu}$ relative to the bulk composition. These findings are discussed in context of intergranular corrosion and the precipitation sequence in $\mathrm{Al}-\mathrm{Cu}-\mathrm{Li}$ alloy.
\end{abstract}

\section{Keywords:}

1. Auger electron spectroscopy (AES),

2. Transmission electron microscopy (TEM),

3. Aluminium alloys,

4. Al-Cu-Li alloys,

5. Grain boundary segregation; 
In recent years, $\mathrm{Al}-\mathrm{Cu}-\mathrm{Li}$ alloys have received increasing attention, driven primarily by the need of reducing weight in aircraft without compromising structural performance $[1,2]$. Due to the low density of $\mathrm{Li}$ and its ability to dramatically reduce alloy density, there have been a number of Li-containing Al-alloys studied over the past several decades. However such Al-Li alloys revealed a number of issues that range from poor fracture toughness to poor corrosion resistance [3]. More recently however, the so-called third generation of Li-containing alloys, which actually have more copper $(\mathrm{Cu})$ than $\mathrm{Li}$ (by mass) have emerged as possessing advantageous property portfolios that are superior to Al-alloys richer in Li. The AA205X and AA209X series, in particular, exhibit a combination of low density, high stiffness and high strength $[1,2,4]$, in addition to low rates of corrosion.

However, despite the favourable specific mechanical properties and general corrosion resistance, the present generation of $\mathrm{Al}-\mathrm{Cu}-\mathrm{Li}$ alloys remain incompletely characterised, particularly with regards to the origin of their unique intergranular corrosion (IGC) and intergranular stress corrosion cracking (IGSCC) response. Conventional aerospace Al-alloys to date (such as the $7 \mathrm{XXX}$ series $\mathrm{Al}-\mathrm{Zn}-\mathrm{Mg}$ alloys) display the maximum resistance to intergranular corrosion in the underaged (i.e. grain boundary precipitate deficient) or the overaged condition (i.e. following grain boundary precipitate coarsened and increased interprecipitate separation). As a result, 7XXX series alloys are nominally not deployed in the peak aged condition where IGC/IGSCC is most rapid. Contrary to the response of 7XXX series alloys, the Al-Cu-Li alloys display the maximum resistance to IGC/IGSCC in the peak-aged condition, with enhanced susceptibility in underaged and overaged conditions [5-9].

The transition from IGC sensitivity in the underaged condition to so-called 'desensitisation' in the peak aged condition has been generally attributed to the distribution of the strengthening $\mathrm{Al}_{2} \mathrm{CuLi}\left(\mathrm{T}_{1}\right)$ precipitates on the alloy surfaces [5, 6, 8-13]. Using conventional wisdom adopted from what is known regarding Li-free age-hardenable Al-alloys, some hypotheses have been put forth to date. For example in underaged alloys (which can include the solution heat treated, quenched and naturally aged condition), $\mathrm{T}_{1}$ precipitates may nucleate at grain boundaries, leading to the formation of $\mathrm{Cu}$ depleted zones. Such $\mathrm{Cu}$ depleted zones may provide a preferential path for dissolution [13-17]. It was proposed that upon further aging, near the peak aged condition, $\mathrm{T}_{1}$ precipitates also forming throughout the grains result in lowering the matrix potential, subsequently reducing the selective dissolution of grain boundary precipitates and propagation of cracks [6, 9, 12, 13, 16, 18, 19]. Meletis et al [7] described the transition from desensitisation back to sensitisation with a similar rationale, which attributed the IGSCC susceptibility in overaged conditions to the formation of large $\mathrm{T}_{1}$ 
precipitates at the grain boundaries associated with the development of strain. Connolly et al $[5,20]$ on the other hand indicated that the $T_{1}$ precipitation sequence is not the key factor in resensitisation but that it results more likely from a combination of different microstructural factors, such as precipitate free zones, grain boundary precipitates, planar slip and solute segregation. Undoubtedly however, the intrinsic mechanisms driving resensitisation remain inadequately understood. Based on the above introduction, two key factors remain in need of further work to better understand the IGC/IGSCC in Al-Cu-Li alloys. These include (i) the detection and rationalisation of the role of $\mathrm{Li}$ in the sensititsation/resensitisation behaviour, and (ii) the microchemistry and microstructure at grain boundaries [21-26].

To date, it has been shown that fracture behaviour of AA2198 and AA2050 was related to solute segregation at grain boundaries, whereby during (over)aging, $\mathrm{Cu}$ controls the growth rate of $\mathrm{T}_{1}$ [27]. This points towards a need for determination of $\mathrm{Cu}$ and $\mathrm{Li}$ concentrations in the vicinity of, and including, grain boundaries. Direct microanalysis of Li segregation is however challenging. Therefore, to accurately quantify grain boundary segregation, the use of unique methods is required, each with their own limitations. Known techniques capable of detecting Li include: electron energy loss spectroscopy (EELS) [28, 29], secondary ion mass spectrometry (SIMS) [30], in situ Auger electron spectroscopy (AES) [31, 32] or atom probe tomography $[29,33]$.

In this study, a combination of conventional transmission electron microscopy (TEM) for structural characterisation, was coupled with in situ Auger electron spectroscopy (AES) to investigate the grain boundary microchemistry and microstructure of AA2050. The latter method was unique on the basis that grain boundaries could be analysed following in-situ fracture at cryogenic temperatures. The chemical composition of the studied AA2050 as determined by inductively coupled plasma atomic emission spectroscopy (ICP-AES) was Al $1.40 \mathrm{Cu}-3.00 \mathrm{Li}-0.19 \mathrm{Mn}-0.36 \mathrm{Mg}-0.04 \mathrm{Ag}-0.10 \mathrm{Si}-0.02 \mathrm{Zr}-0.03 \mathrm{Fe}-0.02 \mathrm{Ti}-0.008$ $\mathrm{Zn}$ (in at. \%). Two different alloy conditions were studied, namely the naturally aged (T351) condition and the overaged $\left(600 \mathrm{~h}\right.$ at $\left.155^{\circ} \mathrm{C}\right)$ condition, in an attempt to characterise the compositional changes at the grain boundaries, and subsequently to contribute towards the mechanisms governing sensitisation. It is understood that the work herein represents a finite contribution to a complex system, and indeed the methodologies required for quantification of Li concentration need to be considered in light of experimental limitations, but nonetheless the present work addresses a unique and timely knowledge gap.

Fig. 1 reveals the general microstructure of the specimens tested, via both scanning and transmission electron microscopy. SEM was carried out using a Jeol 7001F, while TEM was 
carried out using an FEI Tecnai G2 F20 S-TWIN FEG and X-Flash X-Ray detector (Bruker). Thin foils for transmission electron microscopy (TEM) were prepared from $3 \mathrm{~mm}$ discs using twin jet electropolishing (TenuPol-5, Struers) at $12.7 \mathrm{~V}$ in a solution of $33 \%$ nitric acid $-67 \%$ methanol maintained at $-20^{\circ} \mathrm{C}$.

On the micrometre length scale, the backscattered SEM images (Fig 1a, 1c) reveal a typical population of coarse constituent particles (x-ray analysis indicating such particles being rich in $\mathrm{Cu}, \mathrm{Fe}$ and $\mathrm{Mn}$ ) that do not contribute to strength or IGC, and are present in the naturally aged alloy and remain unaltered during over aging. On the nanoscale, Fig. $1 \mathrm{~b}$ reveals an essentially homogeneous feature free microstructure for the T351 condition, where the grain boundary does not appear to have any structural variations (indicative of precipitates) at the conventional length scale. Within grains, there is an absence of discernible lattice reflections for $\mathrm{T}_{1}$ precipitates using selected area diffraction (SAD) patterns (inset Fig. 1b). However, after 600 $\mathrm{h}$ aging at $155^{\circ} \mathrm{C}$, the overaged AA2050 presents strong characteristic reflections of $\mathrm{T}_{1}$ in the $[110]_{\mathrm{Al}}$ direction (inset Fig. 1d), with $\mathrm{T}_{1}$ precipitates visibly evident. Fig. 1d also reveals that $\mathrm{T}_{1}$ is homogeneously distributed in the matrix. However, because grain boundary precipitates (GBPs) do not have a strict orientation relationship with the matrix in projected images, elemental mapping using scanning-TEM was carried out, revealing a strong presence of $\mathrm{Cu}$ (and $\mathrm{Mg}$ ) at the grain boundaries, associated with GBPs. The precise composition of such grain boundary precipitates is not unambiguous from the literature, with reports indicating that GBPs in Al-Cu-Li alloys being coarsened $\mathrm{T}_{1}$, whilst also there exists the possibility of there being $\mathrm{Cu}$-rich GBPs, including $\theta^{\prime}\left(\mathrm{Al}_{2} \mathrm{Cu}\right)$ and $\mathrm{S}^{\prime}$-phase $\left(\mathrm{Al}_{2} \mathrm{CuMg}\right)$, which may form due to local solute saturation and local GB composition - although not necessarily predicted as equilibrium phases from the bulk alloy composition [34, 35].

In order to analyse the GB composition uniquely, an in-situ impact fracture was realised within a PHI 660 scanning Auger microprobe (Physical Electronics). To achieve this, the samples were cooled down to liquid nitrogen temperature and then impact fractured with an in-chamber hammer and a fracture arm. For such experiments, specimens were prepared to conform to the PHI model 192 fracture specimen holder, which required carefully prepared samples of $15 \mathrm{~mm}$ length and $3.14 \mathrm{~mm}$ diameter. A $0.7 \mathrm{~mm}$ notch was machined $10 \mathrm{~mm}$ from the end of the specimen, to facilitate fast fracture. The fracture surfaces are shown in Fig. 2. It is noted that specimens were successfully fractured (Fig. 2a, 2c); and the fracture surfaces present what is predominately brittle fracture. To this end, a small proportion of the surface revealed some ductility in the fracture surface, however the subsequent AES analysis was carried at numerous specific sites that correspond to brittle intergranular fracture (Fig. 2b, 2d), since this allows for 
the determination of compositional changes at GBs. Interestingly, the overaged specimen shows a unique fracture surface pattern, corresponding to a less common morphology, but principally brittle fracture. It merits comment that no methodology is limitation free, and herein, there is a requirement for in situ fracture to avoid surface oxidation or migration of Li due to atmospheric exposure. Such oxidation is prone to occur in other methods, including the focused ion beam milling and transfer to atom probe route, and thus, the pursuit of the in situ AES method herein presents an important path. In order to maximise the information gained from in situ AES, Auger spectra were collected both from the side of the specimen (to represent the sample bulk) and from the freshly prepared fracture surfaces, also providing a comparative contrast as to the difference in composition from the fracture surface, which we believe principally represents GB surfaces. The AES spectra were obtained over a $100 \times 100 \mu \mathrm{m}^{2}$ area, using a $3 \mathrm{kV}$ electron beam with an approximate current of $300 \mathrm{nA}$. The side sample surfaces were sputtered for $45 \mathrm{~min}$ prior to the analysis, using a $3 \mathrm{keV} \mathrm{Ar}^{+}$ion beam rastered over a $1 \mathrm{x}$ $1 \mathrm{~mm}^{2}$ area, to remove the carbon and oxygen surface contamination. The sputter rate was estimated to be around $15 \mathrm{~nm} \mathrm{~min}{ }^{-1}$ under these conditions, assuming a pure $\mathrm{Al}_{2} \mathrm{O}_{3}$ oxyhydroxide layer on the sample surface.

Representative AES spectra obtained from intergranular fracture sites are provided in Fig. 3a and $3 \mathrm{~b}$ for the naturally aged and overaged conditions, respectively. Due to the low peak to background intensity ratio, the AES spectra shown in Figures $3 \mathrm{a}$ and $3 \mathrm{~b}$ have been differentiated to highlight the Auger peaks. Quantification was performed by taking into consideration the peak to peak intensities of the elements detected in the survey scan spectra and the corresponding sensitivity factors provided by the instrument manufacturer [36].

Analysis of multiple sites by AES allows for a consolidated presentation of determined compositions to be presented, shown in Fig. $3 \mathrm{c}$ and $3 \mathrm{~d}$. The $\mathrm{Li} / \mathrm{Al}$ and $\mathrm{Cu} / \mathrm{Al}$ ratios were calculated from the measured concentrations in at. \%. We believe such data has not been previously shown. Firstly, inspecting the Li/Al ratio (Fig. 3c), as anticipated, both the naturally aged and overaged samples have a similar nominal Al/Li composition, in good agreement with the alloy composition determined by ICP-AES. However, the intergranular fracture surfaces, i.e. grain boundaries, of both the naturally aged and overaged AA2050 samples show an enrichment in Li compared to the bulk composition. Of principal interest, it is revealed that the grain boundary regions in the naturally aged AA2050-T351 exhibits a significantly higher $\mathrm{Li} / \mathrm{Al}$ ratio than the bulk alloy composition but also a higher $\mathrm{Li} / \mathrm{Al}$ ratio than the GB region in the overaged sample. The corresponding Li concentration at the naturally aged fracture surface is two to ten times higher than in the bulk. Such a high segregation of $\mathrm{Li}$, whilst perhaps posited 
previously, has not previously been shown (as it is not readily detectible by other means), and provides a stark explanation for IGC in the naturally aged condition by means of electrochemically active grain boundaries. This is also accompanied by the revelation that the $\mathrm{Cu}$ content in the grain boundaries in the naturally aged alloy is much lower than the nominal $\mathrm{Cu}$ content at $<<1$ at. \% (represented by the $\mathrm{Al} / \mathrm{Cu}$ ratio in Fig. $3 \mathrm{~d}$ ).

In contrast to the naturally aged sample, the key principal difference with respect to the GB composition in the overaged condition is that the $\mathrm{Cu} / \mathrm{Al}$ ratio is in excess of the bulk alloy composition, concomitant with the TEM analysis - validating $\mathrm{Cu}$ enriched GBs in the OA condition. The enrichment in $\mathrm{Cu}$ is not associated with an appreciable enrichment in $\mathrm{Li}$, and hence the GB composition between the naturally aged and overaged conditions varies significantly on the spectrum of highly Li enriched and extremely $\mathrm{Cu}$ depleted (naturally aged), to $\mathrm{Cu}$ rich (overaged). Both scenarios correspond to $\mathrm{GB}$ microchemistries that would therefore be anticipated to be susceptible to IGC, one being an electrochemically active (anodic) path, the other being an ennobled grain boundary causing sub-intergranular corrosion (nominally of the Cu-lean PFZ) - as observed in Li-free Al-Cu alloys [37].

Work to date has been unable to provide a quantitative (or perhaps even qualitative) presentation of $\mathrm{Li}$ concentration at $\mathrm{GBs}$ in Al-alloys. Accounting for $\mathrm{Li}$ is critical for understanding the performance of $\mathrm{Al}-\mathrm{Cu}-\mathrm{Li}$ alloys, in particular for IGC phenomena that necessitate Li analysis specifically at GBs. The work herein applied AES to analyse the GB and bulk composition of Al-Cu-Li alloy AA2050 in the naturally aged (T351) and overaged conditions. Despite the limitations in the methodology and techniques applied herein, AES was capable of detecting $\mathrm{Li}$, which is not possible to interrogate using more conventional alternate methodologies. AES analysis of in situ fracture surfaces - which resulted in appreciable but not complete intergranular fracture - was critical to supplement TEM observations which did not reveal GBPs in the naturally aged condition, however AES confirming segregation of Li at the grain boundaries.

\section{Acknowledgments}

This work was financially supported by the Australian Research Council and the Swiss National Science Foundation (Early Postdoctoral Mobility Fellowship P2ELP2_155255). The authors acknowledge use of facilities within the Monash Centre of Electron Microscopy and are grateful to Dr. Katharina Pohl for the fruitful discussion on AES analysis. We gratefully acknowledge Constellium for the supply of the alloy. 


\section{References}

[1] R.J. Rioja, J. Liu, Metall Mat Trans A Phys Metall Mat Sci, 43 (2012) 3325-3337.

[2] T. Dursun, C. Soutis, Mater. Des., 56 (2014) 862-871.

[3] N.J.H. Holroyd, G.M. Scamans, R.C. Newman, A.K. Vasudevan, Chapter 14 - Corrosion and Stress Corrosion of Aluminum-Lithium Alloys, in: N.E. Prasad, A.A. Gokhale, R.J.H. Wanhill (Eds.) AluminumLithium Alloys, Butterworth-Heinemann, Boston, 2014, pp. 457-500.

[4] E.A. Starke, Chapter 1 - Historical Development and Present Status of Aluminum-Lithium Alloys, in: N.E. Prasad, A.A. Gokhale, R.J.H. Wanhill (Eds.) Aluminum-Lithium Alloys, ButterworthHeinemann, Boston, 2014, pp. 3-26.

[5] B.J. Connolly, J.R. Scully, Scripta Mater, 42 (2000) 1039-1045.

[6] R.C. Dorward, K.R. Hasse, Corrosion, 44 (1988) 932-941.

[7] E.I. Meletis, Materials Science and Engineering, 93 (1987) 235-245.

[8] C. Henon, S. Rouault, Comparison of Corrosion Performance and Mechanisms of Al-Cu Alloys with and without Li Addition, in: ICAA13: 13th International Conference on Aluminum Alloys, John Wiley \& Sons, Inc., 2012, pp. 431-436.

[9] E.L. Colvin, S.J. Murtha, R.K. Wyss, Stress Corrosion Cracking Susceptibility of Alloy 2090, in: E.A. Starke, T.H. Sanders (Eds.) Aluminum Alloys - Physical and Mechanical Properties, EMAS, West Midlands, 1986, pp. 1853-1867.

[10] A.K. Vasudevan, J. Liu, R.E. Ricker, Mechanism of Stress Corrosion Crack Growth Resistance of Al-Li-Cu Alloys: Role of Grain Boundary Precipitates, in: M.R. Louthan, R.P. McNitt, R.D. Sisson (Eds.) Environmental Degradation of Engineering Materials III, The Pennsylvania State University, University Park, PA, 1987, pp. 321-327.

[11] M. Guérin, E. Andrieu, G. Odemer, J. Alexis, C. Blanc, in: 14th International Conference on Aluminium Alloys, ICAA 2014, Trans Tech Publications Ltd, Trondheim, 2014, pp. 205-210.

[12] R.G. Buchheit, J.P. Moran, G.E. Stoner, Corrosion, 50 (1994) 120-130.

[13] V. Proton, J. Alexis, E. Andrieu, J. Delfosse, A. Deschamps, F. De Geuser, M.C. Lafont, C. Blanc, Corrosion Science, 80 (2014) 494-502.

[14] F.D. Wall, G.E. Stoner, Corrosion Science, 39 (1997) 835-853.

[15] C. Kumai, J. Kusinski, G. Thomas, T.M. Devine, Corrosion, 45 (1989) 294-302.

[16] R.G. Buchheit, Materials Science Forum, 331-337 (2000) 1641-1646

[17] J.R. Galvele, S.M. de De Micheli, Corrosion Science, 10 (1970) 795-807.

[18] R.G. Buchheit, J.P. Moran, G.E. Stoner, Corrosion, 46 (1990) 610-617.

[19] J.G. Rinker, M. Marek, T.H. Sanders, Materials Science and Engineering, 64 (1984) 203-221.

[20] B.J. Connolly, J.R. Scully, Corrosion, 61 (2005) 1145-1166.

[21] R. Goswami, N. Bernstein, Acta Mater, 87 (2015) 399-410.

[22] S.P. Lynch, R.J.H. Wanhill, R.T. Byrnes, G.H. Bray, Chapter 13 - Fracture Toughness and Fracture Modes of Aerospace Aluminum-Lithium Alloys, in: N.E. Prasad, A.A. Gokhale, R.J.H. Wanhill (Eds.) Aluminum-Lithium Alloys, Butterworth-Heinemann, Boston, 2014, pp. 415-455.

[23] B. Decreus, A. Deschamps, F. de Geuser, P. Donnadieu, C. Sigli, M. Weyland, Acta Mater, 61 (2013) 2207-2218.

[24] B. Decreus, A. Deschamps, F. de Geuser, C. Sigli, Advanced Engineering Materials, 15 (2013) 1082-1085.

[25] T.S. Srivatsan, E.J. Lavernia, J Mater Sci, 26 (1991) 940-950.

[26] B. Decreus, A. Deschamps, P. Donnadieu, J.C. Ehrström, Materials Science and Engineering: A, 586 (2013) 418-427.

[27] B. Gault, F. de Geuser, L. Bourgeois, B.M. Gabble, S.P. Ringer, B.C. Muddle, Ultramicroscopy, 111 (2011) 683-689.

[28] C.M. Sung, H.M. Chang, D.B. Williams, Quantitative microanalysis of Li in binary Al-Li alloys, in: C. Baker, P.J. Gregson, S.J. Harris, C.J. Peel (Eds.) Aluminium-Lithium Alloys III, The Institute of Metals, London, 1986. 
[29] M.J.F. Guinel, N. Brodusch, G. Sha, M.A. Shandiz, H. Demers, M. Trudeau, S.P. Ringer, R. Gauvin, J. Microsc., 255 (2014) 128-137.

[30] J.M. Chabala, R. Levi-Setti, K.K. Soni, D.B. Williams, D.E. Newbury, Applied Surface Science, 51 (1991) 185-192.

[31] R.D.K. Misra, T.V. Balasubramanian, C.R. Chakravorty, Scripta Metallurgica, 21 (1987) 601-606.

[32] J.H. Sanders, Thin Solid Films, 277 (1996) 121-127.

[33] S.P. Ringer, K. Hono, Mater Charact, 44 (2000) 101-131.

[34] K.S. Kumar, S.A. Brown, J.R. Pickens, Acta Mater, 44 (1996) 1899-1915.

[35] J.-F. Li, L. Xu, C. Cai, Y.-L. Chen, X.-H. Zhang, Z.-Q. Zheng, Metall and Mat Trans A, 45 (2014) 5736-5748.

[36] K.D. Childs, B.A. Carlson, L.A. LaVanier, J.F. Moulder, D.F. Paul, W.F. Stickle, D.G. Watson, Handbook of Auger Electron Spectroscopy: a book of Reference Data for Identification and Interpretation in Auger Electron Spectroscopy, Physical Electronics Inc., Minnesota, USA, 1995. [37] J.G. Brunner, N. Birbilis, K.D. Ralston, S. Virtanen, Corrosion Science, 57 (2012) 209-214. 


\section{FIGURES}
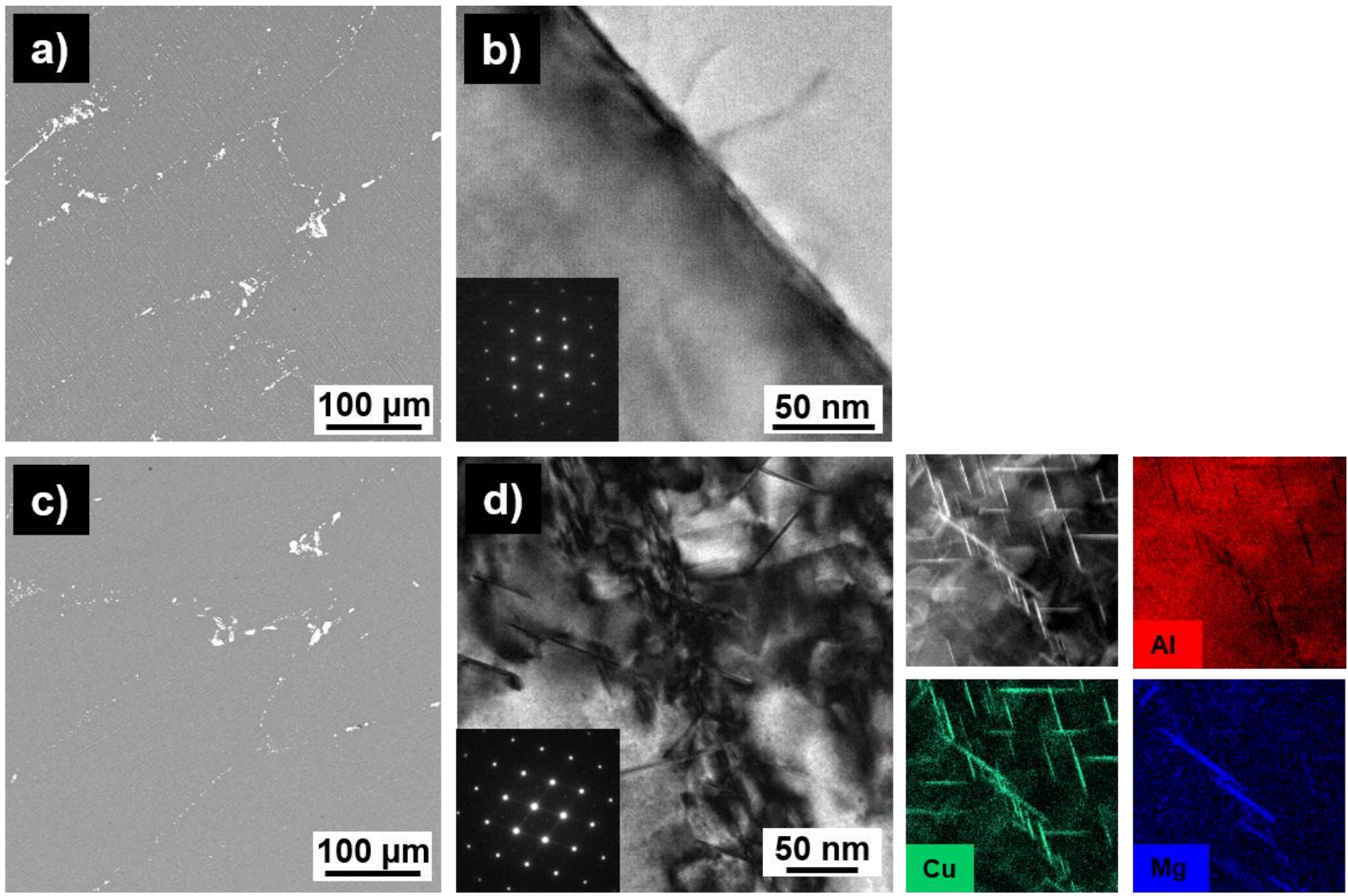

Figure 1: a) BSE-SEM image of AA2050 in the naturally aged (T351) condition, b) BF-TEM image of AA2050 in the T351 condition (inset: corresponding selected area diffraction pattern along [110] $]_{\mathrm{Al}}$ zone axis), c) BSE-SEM image of AA2050 aged for $600 \mathrm{~h}$ at $155^{\circ} \mathrm{C}$ (overaged), d) BF-TEM image of AA2050 aged for $600 \mathrm{~h}$ at $155^{\circ} \mathrm{C}$ presented with DF-TEM image and elemental mapping for $\mathrm{Al}, \mathrm{Cu}$ and $\mathrm{Mg}$ collected in STEM mode (inset: corresponding selected area diffraction pattern along $[110]_{\mathrm{Al}}$ zone axis showing presence on intragranular $\mathrm{T}_{1}$ phase). 

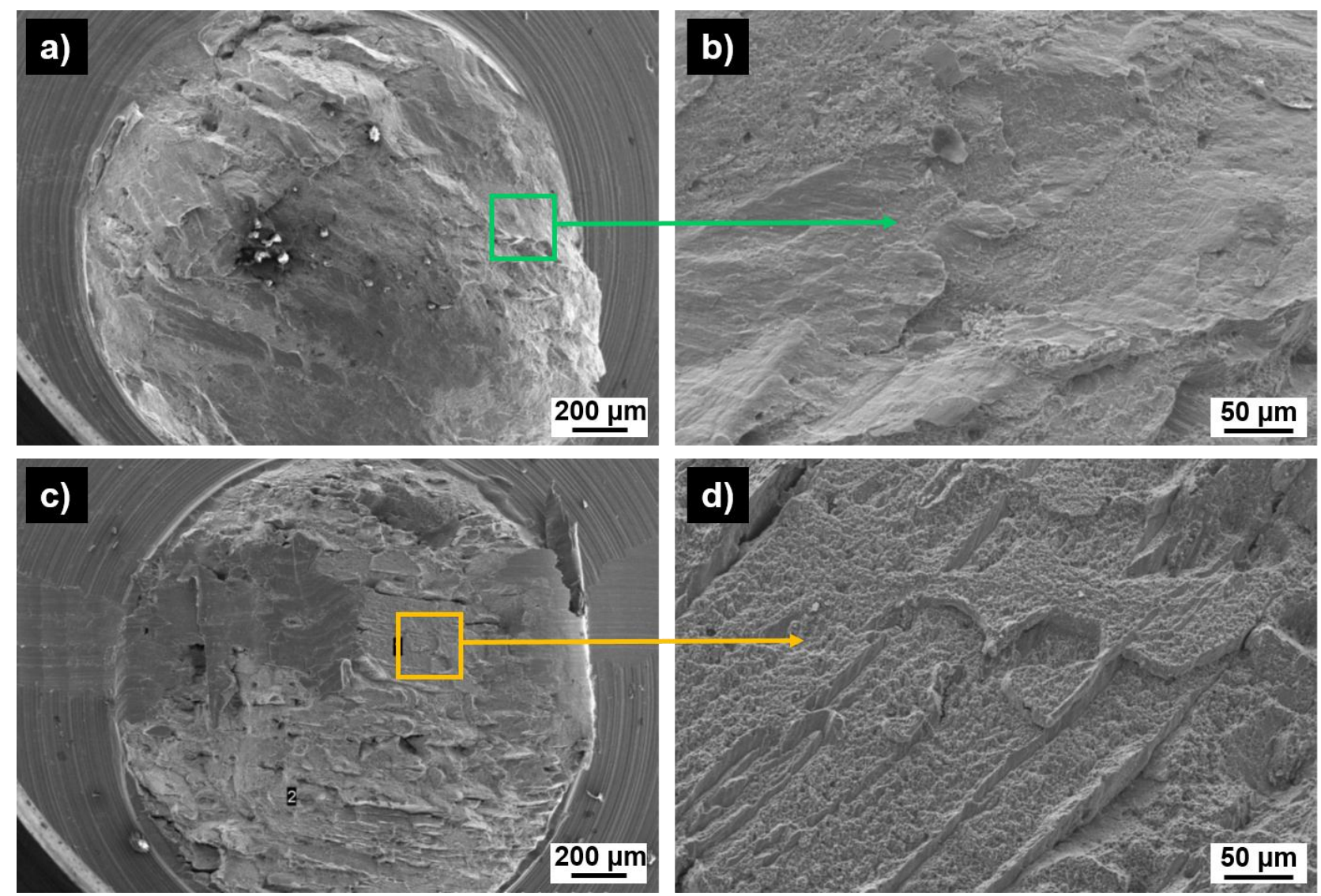

Figure 2: Secondary electron SEM images of the in-situ fracture surfaces of AA2050: a) naturally aged (T351) and c) aged for $600 \mathrm{~h}$ at $155^{\circ} \mathrm{C}$ (overaged). b) and d) representative enlarged areas of surface which reveal a predominately intergranular fracture. 

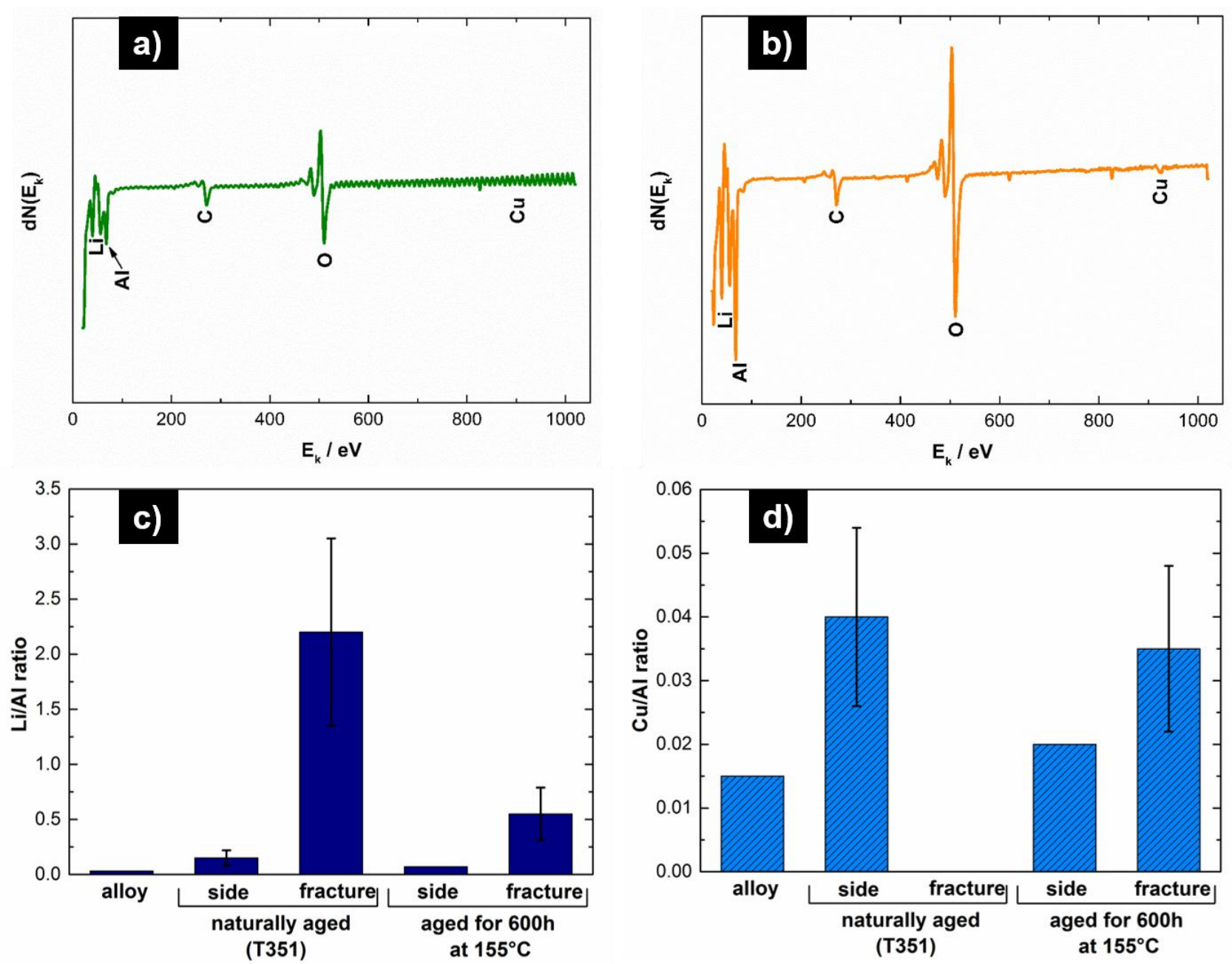

Figure 3. Typical Auger electron spectroscopy (AES) data obtained on the fracture surface of AA2050 for a) the naturally aged (T351) condition, and b) aged for $600 \mathrm{~h}$ at $155^{\circ} \mathrm{C}$ (overaged), c) comparison of the AES determined $\mathrm{Li} / \mathrm{Al}$ ratio, and the d) $\mathrm{Cu} / \mathrm{Al}$ ratio, including the specimen side and the specimen fracture surfaces. 


\section{Graphical Abstract}
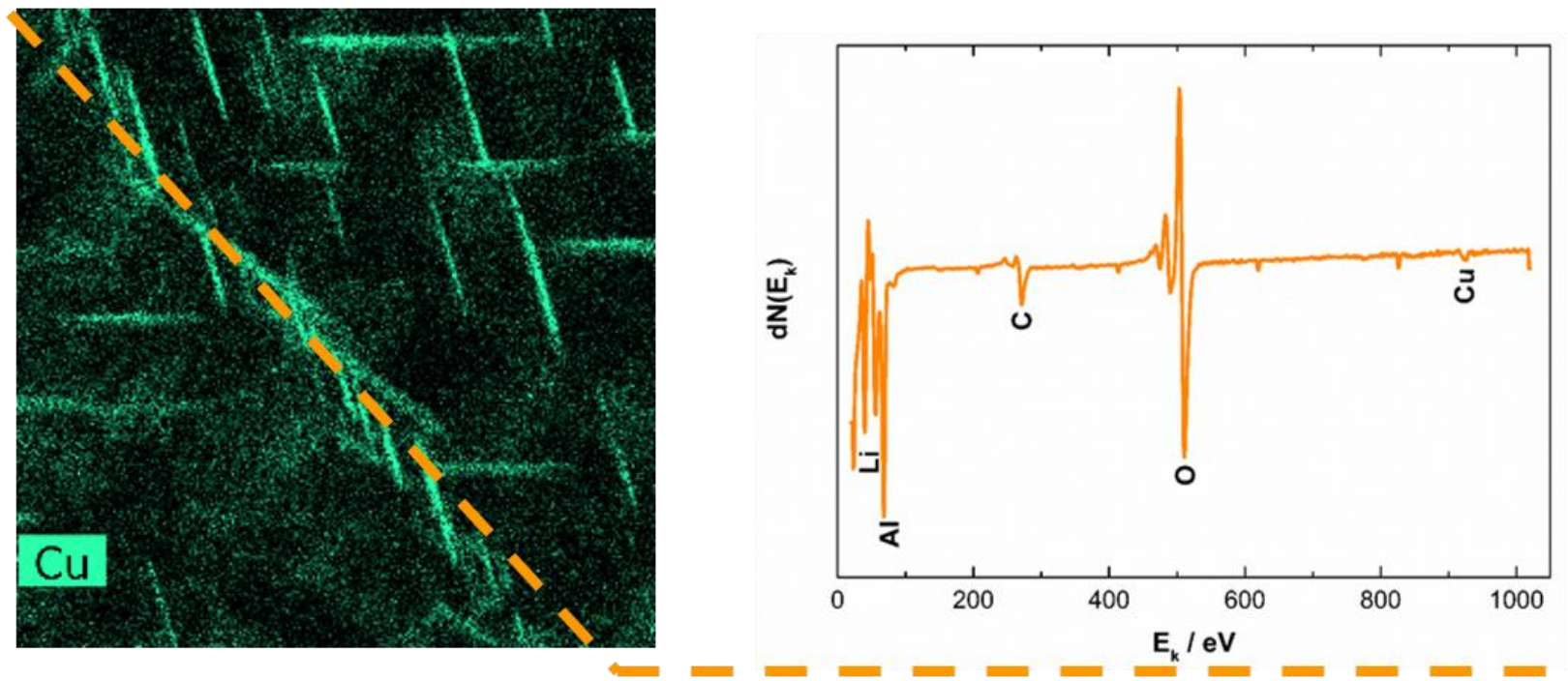